Ambiente \& Água - An Interdisciplinary Journal of Applied Science
ISSN 1980-993X - doi:10.4136/1980-993X
www.ambi-agua.net
E-mail: ambi-agua@agro.unitau.br

\title{
Conflitos no uso da terra em Áreas de Preservação Permanente em um polo de produção de biodiesel no Estado do Pará
}

\author{
doi: 10.4136/ambi-agua.1410 \\ Received: 02 Jun. 2014; Accepted: 13 Aug. 2014 \\ Arlete Silva de Almeida ; Ima Célia Guimarães Vieira \\ Museu Paraense Emílio Goeldi, Belém, PA, Brasil \\ *Autor correspondente: e-mail: arlete@museu-goeldi.br, \\ ima@museu-goeldi.br
}

\section{RESUMO}

As Áreas de Preservação Permanente (APPs) desempenham um papel fundamental na manutenção dos principais fatores que regulam os processos hidrológicos e de conservação biológica. Na Amazônia, as APPs vêm sendo ocupadas com atividades econômicas de alto impacto ambiental que levam à supressão de vegetação, desrespeitando o regime legal desse tipo de área protegida. Este artigo analisa os conflitos de uso da terra dentro das áreas destinadas à preservação e propõe uma delimitação dessas áreas de acordo com o Código Florestal Brasileiro de 2012, no municipio de Moju, um dos mais importantes polos de produção de biodiesel do estado do Pará. A pesquisa utilizou imagem multiespectral de alta resolução do satélite RapidEye de 2010 para uma classificação supervisionada que determinou oito classes de cobertura e uso da terra, com especial atenção para a floresta, o cultivo agrícola e cultivo de óleo de palma (Elaeis guineensis). As terras alteradas do município perfazem $30,29 \%$ do total, sendo que $17,07 \%$ estão ocupadas pela pecuária. Somente 5,2\% do território de Moju é legalmente definido como APP. Destas áreas, 29,3\% se encontram em uso conflituoso, onde predomina a pastagem, presente em 15,6\% das APPs do município. O cultivo de palma corresponde a apenas $0,63 \%$ da área da APP e a $2,17 \%$ do município. A aplicação das novas regras de recomposição de APPs pelo novo Código Florestal Brasileiro irá resultar em perda de 60,69\% de área recuperada em APPs neste município.

Palavras-chave: sensoriamento remoto, classificação supervisionada, cultivo de dendê.

\section{Land use conflicts in Areas of Permanent Preservation in a biodiesel production area in the State of Pará, Brazil}

\begin{abstract}
Areas of Permanent Preservation (APPs) play a crucial role in maintaining some of the most important factors regulating hydrological processes and biological conservation. In Amazonia, APPs are being used in economic activities with high environmental impact in violation of legislation concerning this category of protected land. This leads in turn to the suppression of vegetation. This paper analyzed land use conflicts within APPs and outlined these areas in the municipality of Moju according to the Brazilian Forest Code of 2012. Moju is one of the main biodiesel production centers in the State of Pará. The study used
\end{abstract}


high-resolution multispectral imagery acquired in 2010 by the RapidEye satellite and supervised classification algorithm to determine eight classes of land cover and use, with special attention to forest, agricultural cultivation and oil palm (Elaeis guineensis) cultivation. Altered lands in the municipality amount to $30.29 \%$ of the total, of which $17.08 \%$ is used by livestock. APPs with original vegetation cover (forest and campinarana) constitute $68 \%$ of the municipality area. The loss of $28.29 \%$ of the vegetative cover in local APPs is due mainly to agriculture and animal husbandry. Oil palm cultivation comprises only $0.63 \%$ of the APP and $2.17 \%$ of the municipality areas. Application of the latest guidelines for APPs delimitation according to the new Forest Code will result in the loss of $60.69 \%$ of the APP-recovered areas in this municipality.

Keywords: remote sensing, supervised classification, oil palm cultivation.

\section{INTRODUÇÃO}

Nas últimas décadas presenciamos grandes transformações da região amazônica, a partir de mudanças estruturais no processo de ocupação iniciado em 1960, impulsionadas por programas de desenvolvimento visando integrar a região ao restante do país (Becker, 2007). Essas tranformações tiveram como mola propulsora uma ocupação populacional desenfreada movida por migração espontanea ou estimulada por projeto de colonização, fruto da conjugação entre incentivos fiscais, e a implantação de eixos rodoviários e grandes projetos de mineração (Becker, 2005). As taxas de desmatamento registradas na região variaram de $11.030 \mathrm{~km}^{2} /$ ano em 1991 até um máximo de $27.772 \mathrm{~km}$ /ano alcançado em 1994 (INPE, 2013). Mais recentemente, o desmatamento da Amazônia começou a diminuir, tendo alcançado em 2013 a taxa de $5.843 \mathrm{~km}^{2} /$ ano (INPE, 2013), considerada a segunda mais baixa registrada desde que o início do monitoramento.

A adoção de políticas governamentais que garantam a produção agrícola de maneira a também preservar o meio ambiente é essencial para a manutenção dos ecossistemas naturais. Assim, o Código Florestal Brasileiro de 1965 estabelecia que a vegetação nativa nas margens dos rios e lagos, definidas como Áreas de Preservação Permanente (APP), deveriam ser preservadas. A necessidade de revisão e adequação da Lei de 1965 à realidade atual originou várias Medidas Provisórias (MP), e culminou com a Lei no 12.651, de 25 de maio de 2012, a qual passou a vigorar posteriormente com as alterações estabelecidas na Lei $\mathrm{N}^{\circ} 12.727$, de 17 de outubro de 2012. Essa legislação estabelece as normas gerais para a preservação da vegetação em Áreas de Preservação Permanente e em Áreas de Reserva Legal (RL) e para a recomposição de APPs e RLs, além de outras ações.

A Lei 12.651/12 manteve o mesmo conceito de APP estabelecido no Código de 1965, considerando o seu caráter de preservação e a importância das funções ambientais e de proteção do solo. Porém, indica uma alteração bastante significativa ao estabelecer que as APPs de cursos d'água sejam contabilizadas da borda da calha do leito regular e não do seu nível mais alto. Essa mudança causou muita controvérsia, tendo os cientistas argumentado que o corpo d'água não pode ser entendido somente onde as águas correm na maior parte do tempo, pois o seu leito varia sazonalmente em função das chuvas (SBPC e ABC, 2011). Outra alteração relevante é a nova definição de nascente e olho d'água: o caráter de intermitência foi mantido somente para o último, tendo sido retirado do conceito de nascente. Isso afetou a própria definição de APP, que se refere apenas a áreas de raio mínimo de $50 \mathrm{~m}$ no entorno das nascentes e dos olhos d'água perenes (Lei No 12.727/12).

A lei e o decreto introduziram mecanismos e critérios para a recomposição de áreas degradadas de forma proporcional ao tamanho da propriedade e considerando a temporalidade da degradação. Assim, em se tratando de APPs, foi admitida a continuidade de atividades consolidadas até 22 de julho de 2008, sendo obrigatória a recomposição de determinadas 
faixas de vegetação a depender da extensão da propriedade e da largura do rio, entre outros aspectos.

Há várias décadas as Áreas de Preservação Permanente da Amazônia vêm sofrendo perturbações e degradação devidas à ação antrópica. O processo de uso e ocupação do solo na região é fortemente associado às práticas sociais, econômicas e culturais adotadas pelos produtores (Vieira et al., 2008). Nessa forma de ocupação e uso da terra, a principal atividade econômica praticada é a agropecuária, implantada sem qualquer análise sobre as consequências que o processo de supressão da vegetação em APPs traz para o meio ambiente e para a sociedade.

Uma vez que cada constituinte da cobertura do solo pode ser determinada através de atributos espectrais de textura e forma, é possível ser utilizada técnicas de geoprocessamento de extração direta de informações contidas na paisagem e no mapeamento da cobertura do solo (Ferreira et al., 2005). Estudos feitos com mapas temáticos relacionados ao uso da terra têm servido, de forma geral, como base para as análises de mudanças das formas de uso ao longo do tempo num determinado espaço. Para a execução desse tipo de mapeamento, vêm-se incorporando as geotecnologias, especialmente os produtos oriundos do sensoriamento remoto e o processamento analítico presente nos Sistemas de Informação Geográfica (SIG), os quais são usados como suporte para melhor interpretar o espaço geográfico por meio do tratamento de dados georreferenciados e de sua representação cartográfica (Longley et al., 2002; Silva e Zaidan, 2004).

Neste contexto, o presente trabalho teve por objetivos: delimitar as Áreas de Preservação Permanente no município de Moju, no Estado do Pará, de acordo com as determinações do Código Florestal de 2012; identificar a ocorrência de conflito entre o uso da terra e a legislação; avaliar qual seria o passivo ambiental das APPs ao se aplicarem as novas regras de recomposição, utilizando-se a combinação de tecnologias de sensoriamento remoto e sistemas de informação geográfica.

\section{MATERIAL E MÉTODOS}

\section{1. Área de estudo}

O município de Moju pertence à mesorregião Nordeste Paraense e à microrregião de Tomé-Açu (Figura 1). A área total é de $9.094,10 \mathrm{~km}^{2}$, dista cerca de $60 \mathrm{~km}$ em linha reta da capital do Estado e possui uma população estimada em 70 mil habitantes (IDESP e IMAZON, 2013). Sua economia é baseada no plantio de dendezeiro, produção de madeira, carvão e pecuária.

O relevo apresenta compartimentação discreta: platôs baixos (tabuleiros), terraços fluviais e várzeas. Os tabuleiros apresentam-se aplainados e recobertos por depósitos inconsolidados. O clima característico é o quente e úmido, com temperaturas médias mensais de $25^{\circ} \mathrm{C}$ a $27^{\circ} \mathrm{C}$. A precipitação pluviométrica varia entre 2.000 a $3.000 \mathrm{~mm} / \mathrm{ano}$, sendo o período de janeiro a junho a época mais chuvosa. O rio Moju nasce no município de Rondon do Pará e desagua no rio Guamá, tendo inúmeros afluentes em ambas as margens, os mais expressivos dos quais são da margem esquerda, como os rios Cairari, Mamorama e Pirateua. (IDESP e IMAZON, 2013).

Para a classificação da cobertura vegetal e uso da terra utilizaram-se 29 imagens multiespectrais de 2010 do satélite RapidEye, no Sistema de Coordenadas UTM (Universal Transversa de Mercator), datum WGS84, com 12 bits de resolução radiométrica e $5 \mathrm{~m}$ de resolução espacial das bandas espectrais (Red, Green, Blue, Red Edge, Near IR). 


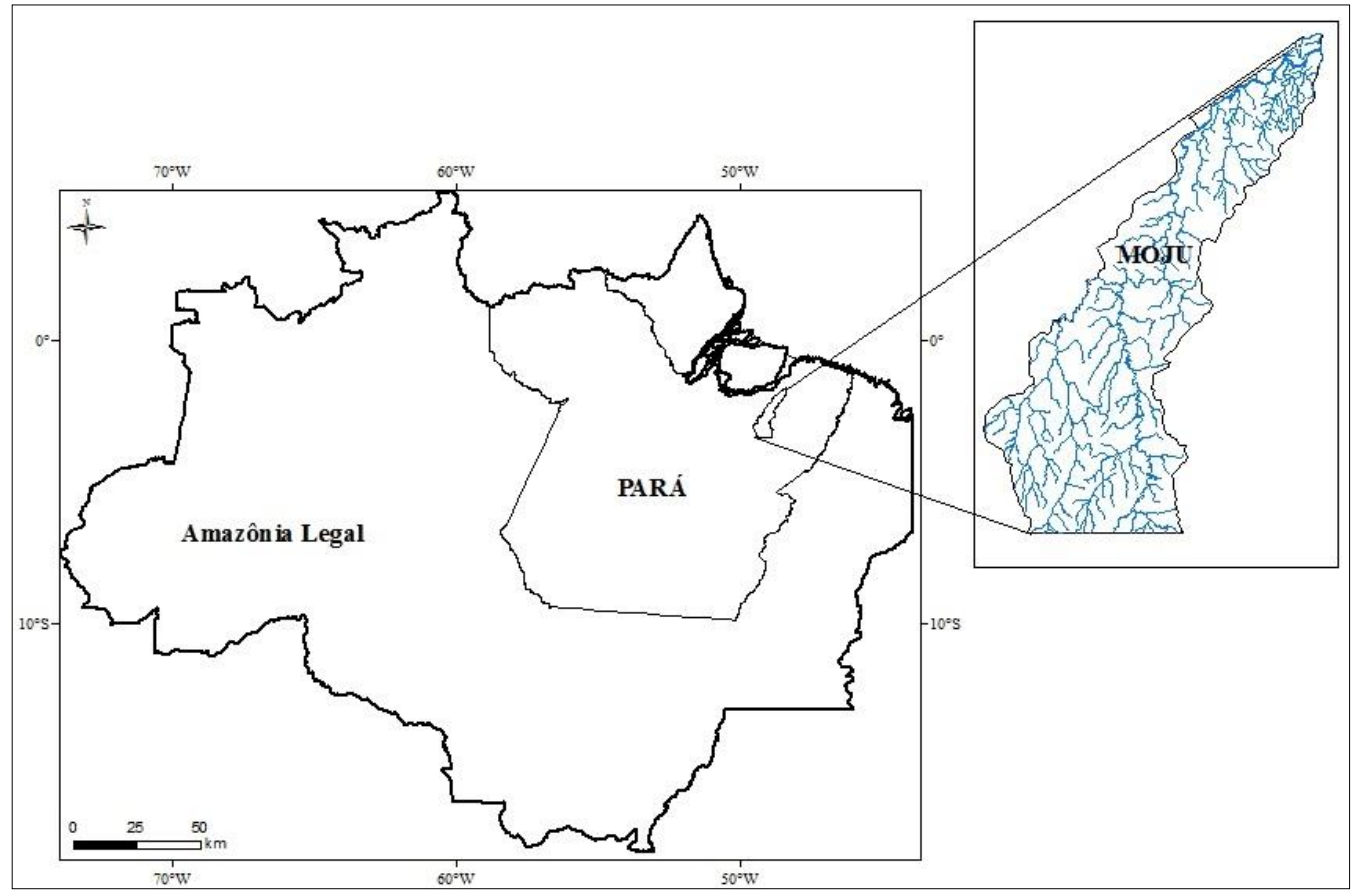

Figura 1. Localização do município de Moju, estado do Pará.

\subsection{Processamento digital}

A classificação supervisionada MaxVer precisa de informações para que o treinador defina qual a probabilidade de uma célula pertencer a uma determinada classe. A distância do valor da célula para o valor central da classe, o tamanho e a forma das classes no espaço são fatores determinantes para a definição da probabilidade. Assim, considerando as classes de floresta primária (terra firme e igapó), floresta secundária (inicial e avançada), dendê, pastagem, área agrícola, área queimada, água, nuvem e sombra, foram definidas as variabilidades de cada banda e canal $(R, G, B)$, sendo determinando os valores centrais de cada classe do treinador.

Após as etapas de classificação da imagem definindo os tipos de uso da terra foi confeccionado o mapeamento identificando as APPs com uso irregular. A qualidade da classificação foi realizada a partir de uma matriz de erro, obtida pelo cruzamento dos dados de campo com informações do mapeamento, que gerou o cálculo da Exatidão Global e Índice de Kappa (Hudson e Ramm, 1987).

\subsection{Delimitação das Áreas de Preservação Permanente}

Os softwares usados para delimitar as APP no municipio foram ESRI ArcGis e Microimages TNT MIPs. Neste trabalho, foram consideradas apenas as APPs ao longo dos cursos d'água e de nascentes, ressaltando que o municipio apresenta topografia moderada de 0 a 30m (IDESP e IMAZON, 2013). Para a delimitação das APPs utilizou-se o banco de dados do IBGE (2010) sobre a rede hidrográfica. A delimitação das APPs foi realizada por meio da geração da zona de tamponamento (buffer) a partir do leito regular dos cursos d’água. A extensão do buffer foi estabelecida de acordo com o Código Florestal Brasileiro (Lei 12.727/2012), que determina as faixas marginais de qualquer curso d'água natural perene e intermitente, excluídos os efêmeros, desde a borda da calha do leito regular, com largura minima definida na Lei 12.651/2012 (Tabela 1). Assim, essa delimitação foi feita a partir da digitalização dos dados vetoriais dos cursos d'água respectivamente com largura de 10, 50, 100, 200 e maior que 600 metros, gerando um delimitador no ArcGIS. As APPs de nascentes 
foram definidas a partir $50 \mathrm{~m}$, tendo como ponto central a nascente, como determina o Código Florestal de 2012.

Tabela 1. Delimitação da largura das APP nos curso d`água em Moju, Pará, Lei $12.651 / 2012$.

\begin{tabular}{cc}
\hline $\begin{array}{c}\text { Largura dos cursos d'água } \\
(\mathrm{m})\end{array}$ & $\begin{array}{c}\text { APP } \\
(\mathrm{m})\end{array}$ \\
\hline$>10$ & 30 \\
10 a 50 & 50 \\
50 a 200 & 100 \\
200 a 600 & 200 \\
$<600$ & 500 \\
\hline
\end{tabular}

A área total das APPs foi determinada a partir da junção de todos os polígonos obtidos pelos diferentes critérios anteriormente descritos. Tal procedimento possibilitou a delimitação e a mensuração de toda a área prevista para preservação, com exclusão das eventuais sobreposições espaciais de APP.

\subsection{Análise de conflito de uso da terra}

Para identificar e analisar os conflitos de uso da terra nas áreas destinadas à preservação, realizou-se a sobreposição do mapa de cobertura vegetal e uso da terra e os polígonos de delimitação das APPs de acordo com o Código Florestal vigente. Logo após a sobreposição fez-se o recorte para determinar a localização das áreas consolidadas e os polígonos obtidos corresponderam exatamente às áreas de usos conflitantes nas APPs.

\subsection{Recomposição de APPs}

A Lei 12.727/2012 estabelece que nas Áreas de Preservação Permanente é autorizada a continuidade das atividades agrossilvipastoris, de ecoturismo e de turismo rural somente em áreas rurais consolidadas até 22 de julho de 2008. O Código define regras específicas para a recomposição dessas áreas e prevê a recomposição escalonada da vegetação nativa, estabelecendo o tamanho da propriedade segundo o módulo fiscal, como critério para a determinação das faixas de recomposição para curso d'água contadas da borda da calha do leito regular, independentemente da largura do curso d'água (Tabela 2). Para calcular a área passível de recomposição, selecionaram-se 608 (49,7\%) que apresentam uso irregular de um universo de 1.224 propriedades registradas no Cadastro Ambiental Rural-CAR, disponível na página da Secretaria de Meio Ambiente do Pará (SEMA): o tamanho das propriedades declarado no CAR possibilitou enquadrá-las na regra do módulo fiscal. Foi necessário realizar mudanças na largura do buffer, devido ao município de Moju apresentar áreas consolidadas com diferentes tipos de uso da terra.

Em caso de áreas rurais consolidadas em APPs no entorno de nascentes e olhos d'água perenes, o novo Código obriga a recomposição em um raio mínimo de 15 (quinze) metros. 
Tabela 2. Critérios de recomposição nos cursos d'água e nascentes em áreas consolidadas até 22 de julho de 2008, de acordo com a lei 12.727/2012.

Módulo Fiscal

Até 1

1 a 2

2 a 4

Superior a 4

Até 10

Nascente

\section{Largura mínima de recomposição}

(m)

5

8

15

\section{0 a 100 (determinado pelo PRA*)}

Somadas todas as APP do imóvel, não ultrapassará $10 \%$ da área total de imóveis rurais com área de até 2 módulos fiscais; e $2 \%$ da área total de imóveis rurais com área superior de 2 a 4 módulos fiscais

\footnotetext{
* PRA - Programa de Regularização Ambiental.
}

\section{RESULTADOS E DISCUSSÃO}

Oito classes de usos e coberturas da terra foram identificadas no município de Moju, distribuídas entre floresta primária, floresta secundária, campinarana, área com dendezeiro, pastagem, área agrícola, área queimada e água. As florestas primárias ocupam 64,28\% da área do município, valor ligeiramente inferior ao encontrado por Almeida et al. (2013) em 2009 (65,96\%, usando imagens Landsat). A área ocupada com floresta primária e floresta secundária é de 73,73\%, o que atribui às autoridades do município uma grande responsabilidade quanto à manutenção e preservação dos remanescentes florestais existentes. Moju apresenta 30,29\% de áreas alteradas, sendo 17,07\% ocupadas pela pecuária. Esse resultado revela que o município acompanha o ritmo de desmatamento do nordeste paraense, com tendência à pecuarização, como evidenciado por Almeida e Vieira (2008) no município de São Francisco do Pará, por Venturieri et al. (2005) em Paragominas e mais recentemente pelo projeto TerraClass, do INPE (INPE e EMBRAPA, 2011).

A validação da classificação realizada por meio da matriz de erro é um indicativo da qualidade da classificação. Assim, obteve-se maior acerto para as classes de plantio de dendezeiro $(96,84 \%)$ e floresta $(95,53 \%)$ e o menor acerto para área agrícola $(50,57 \%)$ e queimada (66,55\%). Isso é comum em estudos no leste da Amazônia, onde há mosaicos agrícolas e áreas de vegetação secundária, pastagens e floresta (Vieira et al., 2003; Almeida e Vieira, 2008). Ao obter a exatidão global de 92,27\% e o índice de Kappa de 0,88, percebemse por esses altos valores que a classificação é satisfatória. O resultado reflete número suficiente de amostras utilizadas para a classificação.

A área destinada legalmente à preservação permanente (APP) em Moju é da ordem de 47.357,06 ha, que representa 5,21\% da área municipal. No entanto, APPs com vegetação natural (florestas primárias e campinarana) representam 68,60\% das APPs do município (Tabela 3), o que, de certa forma, demonstra que o desmatamento de APP não é de grande envergadura e não ocorreu primeiramente nas matas ciliares. Em Paragominas (PA), 
Venturieri et al. (2005) mapearam perdas significativas em matas ciliares no ano de 1996, quando existia cerca de $20,7 \mathrm{~km}^{2}$ de floresta até $1000 \mathrm{~m}$ de distância dos rios, passando para $1,2 \mathrm{~km}^{2}$ em 2004. Watrin et al. (2007) contabilizaram apenas $42,57 \%$ e $54,41 \%$ de área vegetada em duas microbacias de Paragominas, pois a maior parte das APPs ao longo dos rios deste município foram convertidas em pastagem.

Tabela 3. Tipos de Cobertura e Uso da Terra em Moju, destacando o uso irregular de ocupação das Áreas de Preservação Permanente, 2010.

\begin{tabular}{|c|c|c|c|c|}
\hline $\begin{array}{l}\text { Tipos de Cobertura e } \\
\text { Uso da Terra }\end{array}$ & $\begin{array}{c}\text { Área } \\
\text { (ha) }\end{array}$ & $\%$ & $\begin{array}{r}\text { APP } \\
\text { (ha) }\end{array}$ & $\%$ \\
\hline $\begin{array}{l}\text { Vegetação Natural (floresta e } \\
\text { campinarana) }\end{array}$ & $584.554,47$ & 64,28 & $32.485,12$ & 68,60 \\
\hline Floresta secundária & $85.898,57$ & 9,45 & $5.397,88$ & 11,40 \\
\hline Pastagem & $155.260,54$ & 17,07 & $7.397,87$ & 15,62 \\
\hline Culturas agrícolas e queimadas & $14.616,87$ & 1,6 & 301,78 & 0,64 \\
\hline Plantio de dendezeiro & $19.714,43$ & 2,17 & 297,00 & 0,63 \\
\hline Água & $7.697,83$ & 0,85 & -- & -- \\
\hline Nuvem e sombra & $41.667,31$ & 4,58 & $1.477,41$ & 3,12 \\
\hline Área de APP com uso irregular & & & $13.394,53$ & 28,29 \\
\hline Área Total & $909.410,00$ & 100,00 & 47.357,06 & 100,00 \\
\hline
\end{tabular}

A perda de 28,29\% de vegetação natural nas APPs de Moju (APP com uso irregular) é preocupante, na medida em que o Código Florestal atual não garante a recuperação dessas áreas. Esse desmatamento favorece não apenas o processo erosivo, mas também afeta o escoamento superficial e subsuperficial das águas (Figura 2). Alterações na mata ciliar causam modificações na abundância e volume de troncos no canal, afetando principalmente a complexidade estrutural desses ecossistemas, reduzindo o número e as características estruturais das drenagens (Paula et al., 2011). Esse entendimento soma-se ao de Buck et al. (2004), que ressalta que a preservação da mata ciliar impede o acesso do gado ao leito do rio, diminuindo assim os danos nas margens e a contaminação das águas pelas fezes dos animais.

As APPs com uso iregular estão ocupadas principalmente com pastagens e florestas secundárias. As florestas secundárias cresceram após abandono de áreas cultivadas na APP e teriam um importante papel na recomposição de APPs se isoladas de distúrbios, para que possam seguir com a sucessão. Uma APP de qualquer curso d’água deve ter uma largura mínima de 30 metros, aumentando conforme a largura do rio. Dessa forma, a APP, quando existente, atenderia às principais funções ecológicas para a preservação dos mananciais e nascentes de rios. No caso deste município, 16,89\% da vegetação nas APPs já foram suprimidas e estão ocupadas com pastagens e culturas agrícolas, incluindo o dendezeiro. Neste caso, a recomposição dessas APPs depende do tamanho da propriedade e deverá ser feita seguindo os critérios estabelecidos pela nova lei florestal. 


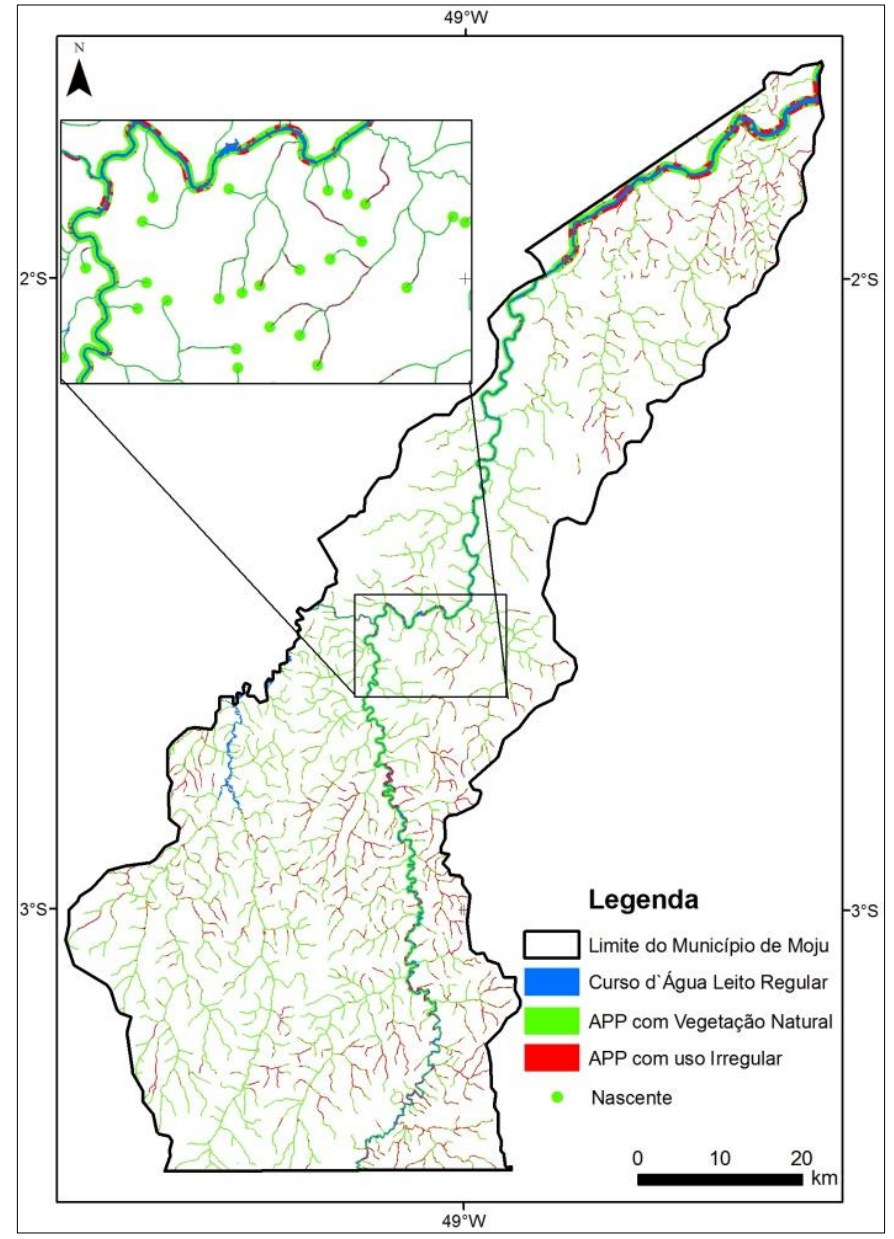

Figura 2. Delimitação das APPs com vegetação natural e com uso irregular no município de Moju-PA.

O dendezeiro (Elaeis guineensis Jacq.) ocupa uma área em APP de 297,00 ha (0,63\% das APPs), valor que pode ser considerado baixo em relação à área total do município $(2,17 \%)$. Ressalta-se que se o plantio estiver concentrado próximo às nascentes, provavelmente esta fração poderá vir a se tornar fator de preocupação. O Programa Nacional de Produção e Uso de Biodiesel (PNPB), criado em 2004 pelo Governo Federal, apontava o dendê como opção mais viável de matéria-prima a ser produzida pela agricultura familiar na Região Norte (Brasil, 2004) e isso tem modificado sobremaneira o padrão de uso da terra nos polos de produção de biodiesel no estado do Pará. Desataca-se que a dendeicultura havia sido vista por muito tempo como econômica e ambientalmente benéfica, contribuindo ainda para a proteção contra a erosão do solo através de plantio consorciado com leguminosas (Homma et al., 2000). Entretanto, ela não deve ser considerada de baixo impacto para a restauração ecológica dessas áreas de proteção, pois plantios homogêneos extensos dessa espécie não contribuem para a conservação da biodiversidade (Lees e Vieira, 2013). O dendezeiro pode até representar uma ameaça para as áreas de APPs no município, uma vez que essa cultura é de altíssimo rendimento e hoje a principal matéria-prima de produção de biodiesel no nordeste paraense. $\mathrm{O}$ aumento de área plantada de dendezeiros poderá resultar em alterações nos ecossistemas da região, e é preciso aumentar o comando e controle no polo de produção de biodiesel para sustar o perigo de expansão do dendezeiro em APPs (Homma e Vieira, 2012).

As áreas de nascente nas regiões nordeste e sudeste do município de Moju são as mais afetadas com a retirada da mata ciliar e a introdução do dendezeiro, que com 297,00 ha ocupa 
nestas regiões suas maiores áreas de plantação. No entanto, considerando a área ocupada com dendezeiro no município (19.714,43 ha), percebe-se que não houve supressão de vegetação em APP em larga escala para o cultivo dessa espécie. Os rios de pequeno porte, de 10 a $30 \mathrm{~m}$ de largura, apresentaram mais de 50\% do total de APP de uso irregular (Figura 2). Este dado é relevante ao considerarmos que são as inúmeras pequenas nascentes que iniciam o fluxo das águas para os rios maiores. A diminuição do volume de água na região pode ocorrer com o assoreamento destas nascentes e destes pequenos curso d'água pela ausência da mata ciliar.

Em 2008, seguindo as determinações do decreto que combate o desmatamento ilegal, o Ministério do Meio Ambiente elaborou uma lista com os 36 municípios que mais desmatam o bioma amazônico. Sete novos municípios foram incluídos na lista no ano seguinte, assim como mais tarde em 2011, quando Moju passou a integrar a relação. Os municípios que constam da lista crítica estão sujeitos a uma série de medidas de controle do desmatamento, como a intensificação da fiscalização ambiental e a consequente restrição de crédito e de mercado, além de serem impedidos de obter licença ambiental mesmo para desmatamento legal. Assim, a inserção dos imóveis rurais no Cadastro Ambiental Rural (CAR) foi uma das medidas adotadas pelo Governo do Estado. Moju já tem 1224 propriedades com cadastro ambiental, sendo 72 definitivos e 1152 provisórios (Pará, 2013) e a área que ocupam é de $679.169,71$ ha, ou seja, 74,68\% do município. Isso não significa que os problemas fundiários estejam resolvidos, pois o cadastro é apenas declaratório.

A análise das 608 propriedades com CAR (499.985,37 ha) mostra que há 9.202,21 ha de passivo ambiental em APPs, considerando tanto o código de 1965 como o de 2012. Porém, somente $3.617,21$ ha estão sujeitos à recomposição. Conforme a lei vigente verifica-se que haverá uma perda de 60,69\% da área total de APPs nessas propriedades, que legalmente deixarão de ser restauradas com a aplicação do novo código florestal (Tabela 4).

Tabela 4. Módulo fiscal e recomposição das APPs de 608 propriedades com Cadastro Ambiental Rural em Moju, PA.

\begin{tabular}{lccc}
\hline Categoria de APP & Módulo Fiscal & Faixas marginais (m) & Área com recomposição (ha) \\
\hline & $<1$ & 5 & 59,28 \\
Curso d’água & $1-2$ & 8 & 101,62 \\
& $2-4$ & 15 & 98,22 \\
Nascente & \multicolumn{1}{c}{20 a 100 (PRA) } & $3349,84 *$ \\
\hline Total & 15 & 8,25 \\
\hline
\end{tabular}

*Cálculo da faixa marginal em $20 \mathrm{~m}$.

Pode-se afirmar, assim, que o novo Código Florestal nos remete a uma situação crítica quanto à manutenção das matas ciliares no município analisado e na Amazônia, por conseguinte, por dar legitimidade às perdas de biodiversidade e de recursos hídricos a partir das mudanças estabelecidas nas regras de recomposição. No Brasil, Soares Filho et al. (2014) estimam que o passivo ambiental com o novo Código Florestal passou a ser de 21 milhões de hectares, sendo $22 \%$ em Áreas de Preservação Permanente nas margens dos rios e $78 \%$ de 
áreas de Reserva Legal. Este valor representa $58 \%$ a menos do que a estimativa anterior, baseada no antigo Código.

As ações ilegais e de desrespeito ao Código Florestal brasileiro, no que concerne à manutenção da floresta natural ao longo dos rios e nascentes, como também a falta de fiscalização e dificuldades na recuperação destas áreas são realidades encontradas nos municípios brasileiros. Os esforços em todos os níveis para modificar a situação atual de gestão ambiental dos municípios da Amazônia, serão importantes para amenizar o passivo ambiental gerado com a nova Lei.

\section{CONCLUSÃO}

A principal forma de uso da terra em Moju refere-se à agropecuária, ocupando $17,07 \%$ da área total. A área preservada com floresta primária de terra firme é de $64,68 \%$ e com florestas secundárias é de $9,45 \%$.

As APPs representam 5,21\% da área total do município, de acordo com os critérios estabelecidos no Código Florestal vigente. No entanto, foi evidenciado conflito no uso da terra em 28,29\% dessas APPs, que são ocupadas principalmente por pastagens e florestas secundárias. O cultivo do dendê ocupou apenas uma fração pequena $(0,63 \%)$ das APPs do município.

Perdas significativas de APPs vêm sendo registradas na Amazônia desde os anos 90, quando projetos agropecuários de larga escala se implantaram na região. Essas APPs deveriam ser recompostas a partir de iniciativas de restauração florestal, como exigido pelo código florestal de 1965. No Pará, uma governança florestal mais forte iniciou-se em 2007 com a exigência da recomposição florestal de APPs e reservas legais por decretos e leis estaduais. No entanto, o código florestal atual, embora não tenha alterado os critérios de preservação de APP, passou a considerar o tamanho da propriedade (módulos rurais) e a largura do rio como critérios essenciais para a recomposição de APP, alterando sobremaneira a quantidade de área com uso irregular a ser recomposta. É como se tivéssemos duas leis: uma para preservação e outra para recomposição. A análise feita neste trabalho com $50 \%$ das propriedades com Cadastro Ambiental Rural mostrou que 61\% de APPs com uso irregular, que representam 5.584,82 ha do total de APPs, não sofrerão recomposição de acordo com o Código vigente, deixando um considerável passivo ambiental no município. Pelo Código anterior, todos os $13.394,53$ ha $(28,29 \%)$ de APP com uso irregular no município deveriam ser recompostos.

A principal contribuição deste estudo, para o município de Moju e o Estado do Pará é evidenciar a situação ambiental das APPs e fornecer informação que pode ser usada pelos órgãos responsáveis pela gestão ambiental para o desenvolvimento de projetos de adequação e recomposição de APPs com usos irregulares e preservação de APPs intactas. Porém, sabe-se que há inúmeras dificuldades operacionais na estruturação da gestão ambiental municipal e somente com medidas de controle, um programa sério de restauração ecológica e maior governança ambiental pode-se conseguir recuperar pelo menos parte do passivo ambiental existente nas APPs do município.

\section{AGRADECIMENTOS}

Os autores agradecem o apoio e os recursos financeiros do Conselho Nacional de Pesquisa e Desenvolvimento Tecnológico (CNPq) por meio do projeto INCT/ Biodiversidade e Uso da Terra na Amazônia (CNPq 574008/2008-0) e da bolsa de produtividade concedida a Ima Célia Guimarães Vieira (CNPq 306368/2013-7); ao Programa de Pós-graduação em Ciências Ambientais (PPGCA) da Universidade Federal do Pará (UFPA) em convênio com o 
Museu Paraense Emilio Goeldi e Embrapa Amazônia Oriental pela oportunidade de doutorado de Arlete Silva de Almeida e aos revisores deste artigo por suas recomendações valiosas.

\section{REFERÊNCIAS}

ALMEIDA, A. S.; VIEIRA, I. C. G.; ROCHA, D. P. N. Cenários para a Amazônia: clima, biodiversidade e uso da terra. Caracterização e mapeamento dos padrões de uso da terra na área de endemismo Belém. Boletim do Museu Paraense Emílio Goeldi, p. 170, 2013.

ALMEIDA, A. S.; VIEIRA, I. C. G. Dinâmica da cobertura vegetal e uso da terra no município de São Francisco do Pará (Pará, Brasil) com o uso da técnica de sensoriamento remoto. Ciências Naturais, v. 3, n. 1, p. 81-92, 2008.

BRASIL. Presidência da República. Decreto no 5.298 de 6 de dezembro de 2004. Altera a alíquota do Imposto sobre Produtos Industrializados incidente sobre o produto que menciona. Disponível em: <http://www.presidencia.gov.br〉. Acesso em: 01 set. 2013.

BECKER, B. K. Amazônia: geopolítica na virada do III milênio. Rio de Janeiro: Garamond, 2007. p. 23-25.

BECKER, B. K. Geopolítica da Amazônia. Estudos Avançados, v. 19, n. 53, 2005. http://dx.doi.org/10.1590/S0103-40142005000100005

BUCK, O.; NIYOGI D. K.; TOWNSEND, C. R. Scale-dependence of land use effects on water quality of streams in agricultural catchments. Environmental Pollution, Braking, v. 130, p. 287-299, 2004. http://dx.doi.org/10.1016/j.envpol.2003.10.018

FERREIRA, L. V.; VENTICINQUE, E.; de ALMEIDA, S. S. O desmatamento na Amazônia e a importância das áreas protegidas. Estudos Avançados, v. 19, n. 53, p. 1-10. 2005. http://dx.doi.org/10.1590/S0103-40142005000100010

HOMMA, A. K. O.; FURLAN JÚNIOR, J; CARVBALHO, R.; A.; FERREIRA A. Bases para uma política de desenvolvimento da cultura do dendê na Amazônia. In: VIEGAS, I. J. M; MULleR, A. A. (Orgs.). A cultura do dendezeiro na Amazônia brasileira. Belém: Embrapa Amazônia Ocidental, 2000. p. 11-30.

HOMMA, A. K. O; VIEIRA, I. C. G. Colóquio sobre dendezeiro: prioridades de pesquisas econômicas, sociais e ambientais na Amazônia. Amazônia: Ciência \& Desenvolvimento, v. 8, n. 15, p. 79-90, 2012.

HUDSON, W. D.; RAMM, C. W. Correct formulation of the kappa coefficient of agreement. Photogrammetric Engineering \& Remote Sensing, v. 53, n. 4, p. 421-422, 1987.

INSTITUTO BRASILEIRO DE GEOGRAFIA E ESTATÍSTICA - IBGE. Downloads, Geociências. 2010. Disponível em: 〈http://www.ibge.gov.br>. Acesso em: dez. 2013.

InSTITUTO NACIONAL DE PESQUISAS ESPACIAIS - INPE. Projeto PRODES: monitoramento da Floresta Amazônica brasileira por satélite. 2013. Disponível em: <http:// www.obt.inpe.br/prodes/index.php>. Acesso em: 20 dez. 2013. 
INSTITUTO NACIONAL DE PESQUISAS ESPACIAIS - INPE; EMPRESA BRASILEIRA DE PESQUISA AGROPECUÁRIA - EMBRAPA. Projeto TerraClass. 2011. Disponível em: <www.inpe.br/cra/projetos_pesquisas/terraclass2010.php>. Acesso em: 20 dez. 2013.

INSTITUTO DE DESENVOLVIMENTO ECONÔMICO SOCIAL E AMBIENTAL DO PARÁ - IDESP; INSTITUTO DO HOMEM E MEIO AMBIENTE DA AMAZÔNIA IMAZON. Programa Municípios Verdes: diagnóstico da gestão ambiental dos municípios paraenses. Belém, 2013. 53 p.

LEES, A. C.; VIEIRA, I. C. G. Oil-palm concerns in Brazilian Amazon. Nature, v. 497, p. $188,2013$.

LONGLEY, P. A.; GOODCHILD, M. F.; MAGUIRRE, D. J.; RHIND, D. W. Geographic information systems and science. New York: John Wiley \& Sons, 2002.

PARÁ. Secretaria de Estado do Meio Ambiente. Sistema integrado de monitoramento e licenciamento ambiental - Módulo Público (SIMLAM Publico). 2012. Disponível em; <http://monitoramento.sema.pa.gov.br/simlam/, acesso em junho 2013>. Acesso em dez. 2013.

PAULA, F. R.; FERRAZ, S. F. B.; GERHARD, P.; VETTORAZZI, C. A.; FERREIRA, A. Large woody debris input and its influence on channel structure in agricultural lands of Southeast Brazil. Environmental Management, v. 48, p. 750-763, 2011. http://dx.doi.org/10.1007/s00267-011-9730-4

SOCIEDADE BRASILEIRA PARA O PROGRESSO DA CIÊNCIA - SBC; ACADEMIA BRASILEIRA DE CIÊNCIAS - ABC. O código florestal e a ciência: contribuições para o diálogo. São Paulo: SBPC, 2011.

SILVA, J. X. DA; ZAIDAN, R. T. Geoprocessamento e análise ambiental: aplicações. Rio de Janeiro: Bertrand Brasil, 2004.

SOARES FILHO, B. S.; RAJÃO, R.; MACEDO, M.; CARNEIRO, A.; COSTA, W. L. S.; COE, M. et al. Cracking Brazil's forest Code. Science, v. 344, p. 363-364, 2014

VENTURIERI, A.; FIGEIREDO, R.; WATRIN, O. S.; MARKEWITZ, D. Utilização de imagens Landsat e CBERS na avaliação da mudança do uso e cobertura da terra e seus reflexos na qualidade da água em microbacia hidrográfica do município de Paragominas, Pará. In: SIMPÓSIO BRASILEIRO DE SENSORIAMENTO REMOTO, 12., 2005, Goiânia. Anais... São José dos Campos: INPE, 2005. v. 1., p. 1127-1134.

VIEIRA, I. C. G.; TOLEDO, P. M. de; SILVA, J. M. C. da; HORÁCIO, H. Deforestation and threats to the biodiversity of Amazonia. Brazilian Journal of Biology, v. 68, p. 631637, 2008. http://dx.doi.org/10.1590/S1519-69842008000500004

VIEIRA, I. C. G.; ALMEIDA, A. S. de. DAVIDSON, E. A.; STONE, T. A.; CARVALHO, C. J. R. de; GUERRERO, J. B. Classifying successional forests using Landsat spectral properties and ecological characteristics in eastern Amazônia. Remote Sensing of Environment, v. 87, n. 4, p. 470-481, 2003. http://dx.doi.org/10.1016/j.rse.2002.09.002

WATRIN, O. S.; MACIEL, M. N. M.; THALES, M. C. Análise espaço-temporal do uso da terra em microbacias hidrográficas no município de Paragominas, Estado do Pará. In: SIMPÓSIO BRASILEIRO DE SENSORIAMENTO REMOTO, 13., 2007, Florianópolis. Anais... São José dos Campos: INPE, 2007. p. 7019-7026. 